\title{
Garlic greening: Pigments' biosynthesis and control strategies
}

\author{
Alberto De Iseppi, Andrea Curioni, Matteo Marangon, Simone Vincenzi* and Giovanna Lomolino \\ Department of Agronomy, Food, Natural Resources, Animals and Environment (DAFNAE), University of Padova, Viale \\ Dell'Università, 16-35020 Legnaro (Padova), Italy
}

*Corresponding Author: Simone Vincenzi, Department of Agronomy, Food, Natural Resources, Animals and Environment (DAFNAE), University of Padova, Viale dell'Università 16, 35020 Padova, Italy. Email: simone.vincenzi@unipd.it.

Received: 25 July 2020; Accepted: 14 January 2021; Published: 13 February 2021

(c) 2021 Codon Publications

OPEN ACCESS (c) (우웅

REVIEW

\begin{abstract}
Greening is a major problem for garlic's quality. This phenomenon leads to discoloration of the product and is directly related to the alliinase-catalyzed conversion of isoalliin into 1-propenyl-containing thiosulfates. Garlic crushing, refrigeration, and storage in normal atmosphere, as well as in the presence of monocarboxylic acids, are established the main factors that promote its greening. In last decades, the study of biochemical pathway of this phenomenon has allowed to effectively understand the main steps and key enzymes involved, and to identify optimum conditions for chemical and enzymatic reactions leading to discoloration. These findings have, in some cases, determined the development of new tools for the control of garlic greening on large scale. After providing an updated description of the biochemistry of green pigments produced in garlic, this review reports an overview on the strategies for controlling discoloration of garlic at industrial level.
\end{abstract}

Keywords: control strategies, discoloration, garlic, greening, isoalliin, $S$-alk(en)ylcysteine sulfoxides

\section{Introduction}

Garlic (Allium sativum) is a world-spread plant being used for centuries as a food for its health benefits (Banerjee et al., 2003). Its health benefits have been exploited to treat diseases starting from ancient Sumerians, Egyptians, Greeks, and Romans up to the modern times (Zang et al., 2013). Garlic cultivation was probably started in central Asia for more than 10,000 years ago (Block, 2010). Nowadays also, garlic cultivation is primarily concentrated in the same region, with China, India, and Bangladesh accounting for $86 \%$ of the world's production (FAOSTAT, 2016).

Garlic is a fundamental ingredient of many food preparations. Indeed, thanks to its antimicrobial properties and distinctive taste, it is used as a food preservative and/or seasoning in many typical recipes, and has become a key component of the Mediterranean cuisine (Lanzotti, 2006). Essentially, owing to its high content of sulfur aroma compounds (Speranza and Morelli, 2012), garlic is widely used as a taste and flavor enhancer of recipes all over the world. In these preparations, fresh garlic cloves are usually crushed immediately before use, a process that is essential to release the sulfur-containing compounds responsible for its typical flavor (Block, 1992). Indeed, crushing allows enzyme alliinase, which is originally found in cell vacuole, to get in contact with $S$-alk(en)ylcysteine sulfoxides, such as isoalliin and alliin, and convert them into 1-propenyl-containing thiosulfinates and allicin, respectively (Kubec and Velíšek, 2007). This latter compound is in turn the precursor for many flavoring molecules such as diallyl disulfide and diallyl sulfide (Yoshimoto et al., 2019). In addition, the isoalliin degradation pathway leads to the synthesis of 1-propenyl-containing thiosulfinates, which are recognized as "color developers," i.e., compounds responsible for garlic greening (Kubec and Velíšek, 2007; Kubec et al., 2004). This phenomenon of discoloration, generally desirable for many Asiatic preparations (i.e., Laba garlic; 


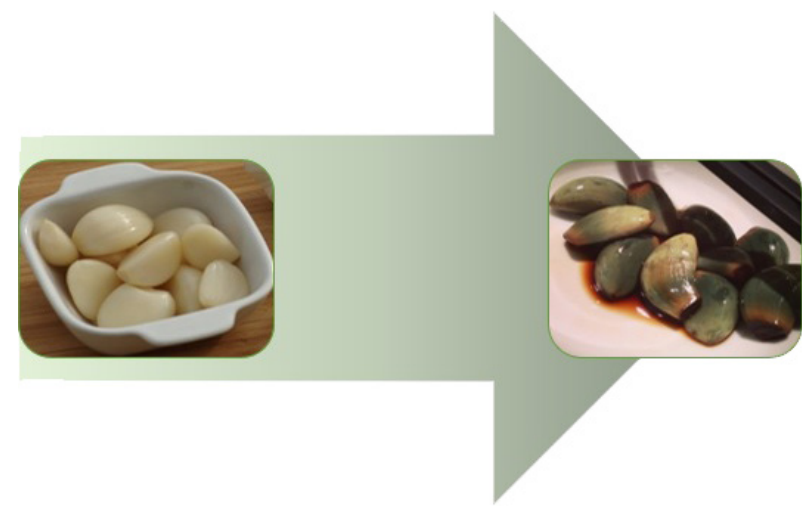

Figure 1. Greening in Laba garlic (retrieved from commons. wikimedia.org).

Figure 1), is undesirable in western countries, where any variation from the white color negatively affects garlic's marketability (Tao et al., 2016).

Formation of pigment cannot be inhibited drastically (i.e., by interventions at the genetic level) as it shares the same biosynthetic pathway of bioactive and flavor compounds. Therefore, the phenomenon of greening needs to be controlled by preventive practices during garlic storage and/or processing (Zang et al., 2013).

Many papers, reporting on the mechanisms of production of allicin (and related compounds), have primarily focused on their flavoring and health properties. In contrast, fewer and less recent works have dealt with the problem of garlic discoloration by analyzing the main greening controlling strategies employed at industrial level.

In this review, an updated biochemical description of the biosynthetic pathway leading to the production of pigments in garlic is reported. Subsequently, the available and possible new technologies to control garlic greening are described, and discussed critically.

\section{Pigments' Formation}

The starting point of pigments' biosynthesis is the conversion of isoalliin and other $S$-alk(en)ylcysteine sulfoxides into 1-propenyl-containing thiosulfinates (Kubec and Velíšek, 2007; Kubec et al., 2004). This biochemical process gained more and more interest starting from the middle of the 20 th century when $S$-alk(en)ylcysteine sulfoxides, including alliin, isoalliin, and methiin, as well as their conversion into allicin by the enzyme alliinase, were first described (Stoll and Seebeck, 1948, 1949a, 1949b, 1951).

A schematic overview on the main biochemical steps leading to the pigment's biosynthesis in Allium sativum plants is described in Figure 2 (Imai et al., 2006b; Zang et al., 2013). These different steps are discussed in detail in the following sections.

\section{Biosynthesis of S-alk(en)ylcysteine sulfoxides}

$S$-alk(en)ylcysteine sulfoxides are present in all plants belonging to the genus Allium, especially alliin ( $S$ allylcysteine sulfoxide) and isoalliin ( $S$-1propenylcysteine sulfoxide) (Martins et al., 2016). These compounds comprise analk(en)yl group, probably originating from valine catabolism, and a cysteine moiety derived from glutathione. The currently proposed alliin and isoalliin biosynthesis pathway (Figure 3 [Yoshimoto et al., 2019]), recently reviewed by Yoshimoto et al. (2019), includes: (i) the conjugation of glutathione to methacrylic acid or methacrylic-CoA (both derived from valine catabolism) to form $S$-(2-carboxypropyl) glutathione (Granroth, 1970; Lancaster and Shaw, 1989; Suzuki et al., 1962); (ii) the formation of $\gamma$-glutamyl-S-1propenylcysteine and $\gamma$-glutamyl- $S$-allylcysteine (precursors of isoalliin and alliin, respectively) after removal of glycyl from $S$-(2-carboxypropyl) glutathione and its conversion into the $S$-1-propenyl and/or $S$-2-propenyl group by oxidative decarboxylation; (iii) the sulfide forma-tion after removal of the $\gamma$-glutamyl group catalyzed by $\gamma$ glutamyl transpeptidases enzyme (GGT); and (iv) the $S$ oxygenation of intermediate sulfides into alliin and isoalliin catalyzed by a flavin-containing $S$-oxygenase.

The reactions described at above-mentioned (i) and (ii) are probably catalyzed by still unknown enzymes. Conversely, the roles of GGT and flavin-containing $S$-oxygenase were assessed at molecular level (Cho et al., 2012b; Yoshimoto et al., 2015), and recently a consensus has been reached on this point (Yoshimoto et al., 2019).

Even though it is known that $S$-alk(en)ylcysteine sulfoxides are accumulated in cytosol, the subcellular localization of several of the biosynthetic reactions described above has not been completely clarified (Yoshimoto et al., 2019). Indeed, many of the above-mentioned enzymes and intermediates are probably located in different cell compartments of Allium plants. In garlic, the flavin-containing $S$-oxygenase is located in the cytosol (Yoshimoto et al., 2015), and in onion (Allium cepa), which presents a similar $S$-alk(en)ylcysteine sulfoxides biosynthetic pathway and cell structure, $\gamma$-glutamyl peptides have been detected also in the cytosol, while glutathione was found in both cytosol and chloroplasts (Lancaster and Collin, 1981; Lancaster and Shaw, 1989). Conversely, GGT enzyme and methacrylic-CoA have never been precisely localized in Allium spp., although in plant cells they are usually found in vacuoles and mitochondria, respectively (Binder, 2010; Grzam et al., 2007). 


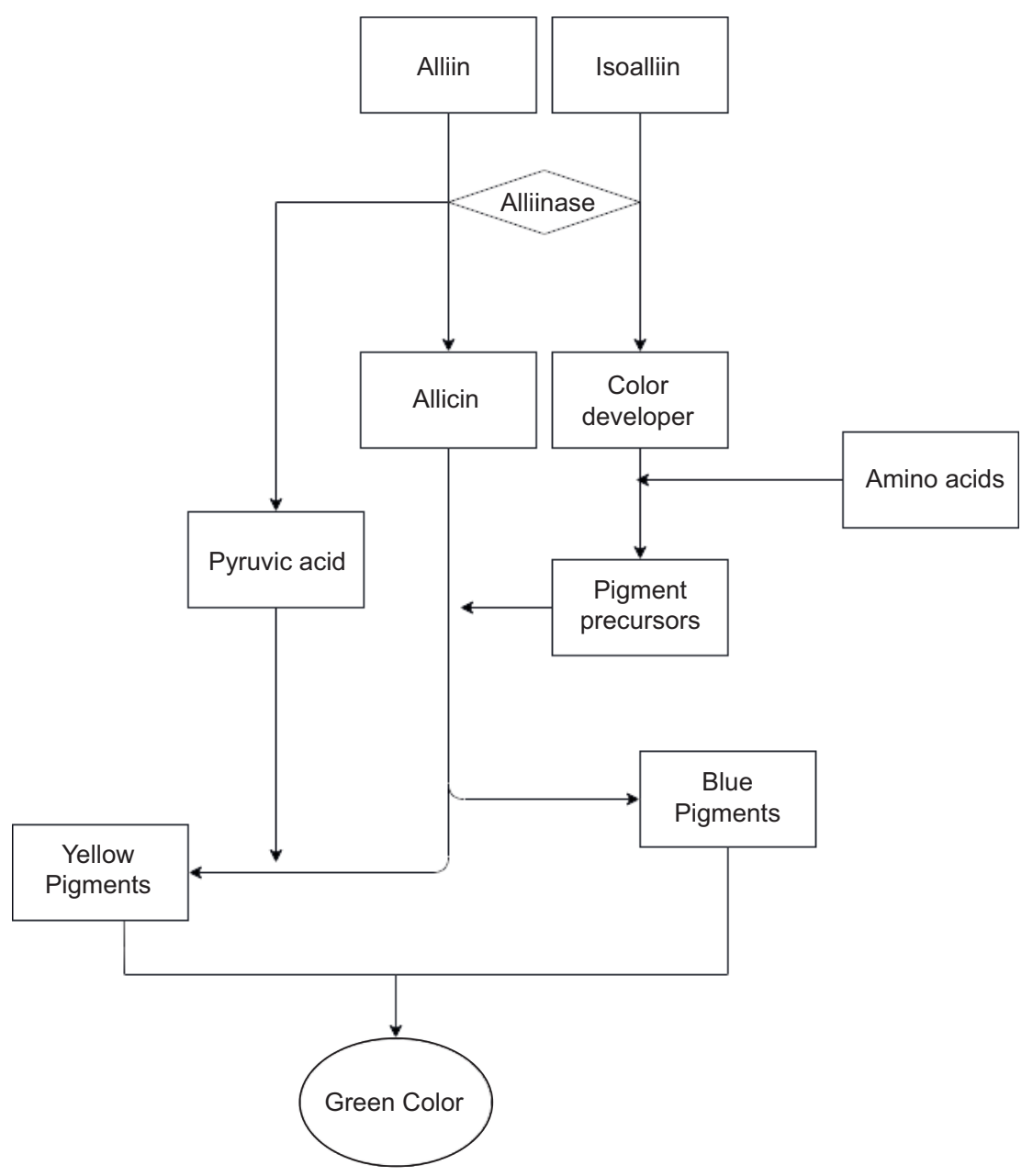

Figure 2. Main steps involved in pigments' biosynthesis pathway in garlic (Allium sativum) plants.

Allium plants synthesize $S$-alk(en)ylcysteine sulfoxides in a manner to accumulate nitrogen and sulfur as well as a defense mechanism against insects and pathogens (Aghajanzadeh et al., 2019; Yoshimoto et al., 2019).

\section{Biosynthesis of thiosulfinates}

In Allium plants, thiosulfinates are produced from the hydrolysis of $S$-alk(en)ylcysteine sulfoxides, which are catalyzed by the enzyme alliinase, a pyridoxal $5^{\prime}$-phosphate (PLP)-dependent C-S lyase (EC 4.4.1.4). Since alliinase is located in the vacuole and the $S$-alk(en)ylcysteine sulfoxides are stored in the cytosol, this reaction takes place only after crushing, cutting, maceration, or other practices leading to cell disruption (Lancaster and Collin, 1981; Li et al., 2015). Upon contact, alliinase removes a proton attached to the chiral carbon of the $\mathrm{S}$-alk(en)ylcysteine sulfoxide, cleaving the $\mathrm{C}-\mathrm{S}$ bond to yield sulfenic acid, pyruvic acid, and ammonia (Shimon et al., 2007). Sulfenic acids are then converted into thiosulfinates by spontaneous self-condensation (Yoshimoto et al., 2019). In onion, this step could be partially hindered by the activity of the enzyme lachrymatory factor synthase (LFS), which converts isoalliin into propanethial $S$-oxide, the "lachrymatory factor," which is the compound involved in lachrymation during slicing of onions (Imai et al., 2002; Silvaroli et al., 2017).

In garlic, 1-propenyl-containing thiosulfinates derived from isoalliin are called "color developers." A minor but significant role is played in the greening of garlic by the alliin-derived thiosulfinate allicin (Figure 4 [Kubec et al., 2017]). Allicin is established as the main thiosulfinate in garlic, where it is the principal responsible for the development of typical flavors and health-benefit properties (Borlinghaus et al., 2014; Kopec et al., 2013; Martins et al., 2016; Rahman, 2007).

However, for the greening phenomenon, the main role is played by isoalliin-derived 1-propenyl-containing thiosulfinates ("color developers"), as they constitute the basic structure for the formation of pigment precursors (Figure 2; Kubec et al., 2004, 2017; Zang et al., 2013). 


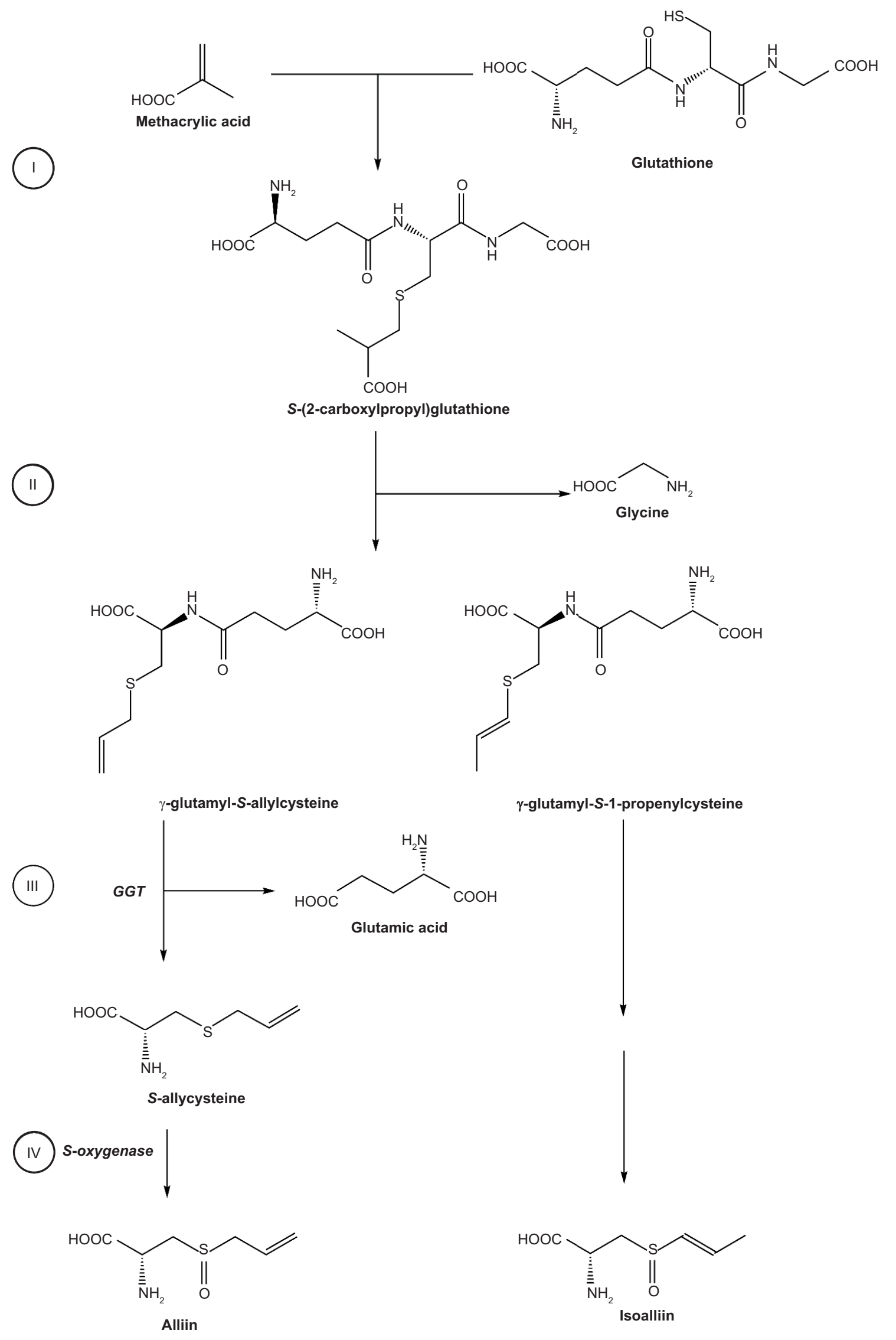

Figure 3. Biosynthetic pathways for alliin and isoalliin formation. 


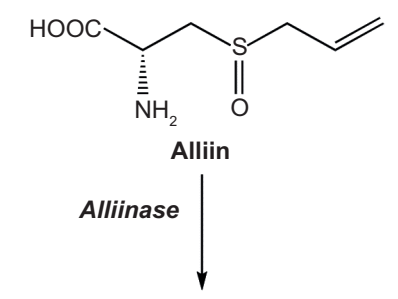<smiles>C/C=C/S(=O)C[C@H](N)C(=O)O</smiles><smiles>C=CCSS(=O)CC=C</smiles><smiles>C/C=C/S[Sb]([O-])/C=C/C</smiles>

di-1-propenyl thiosulfinate Color developer
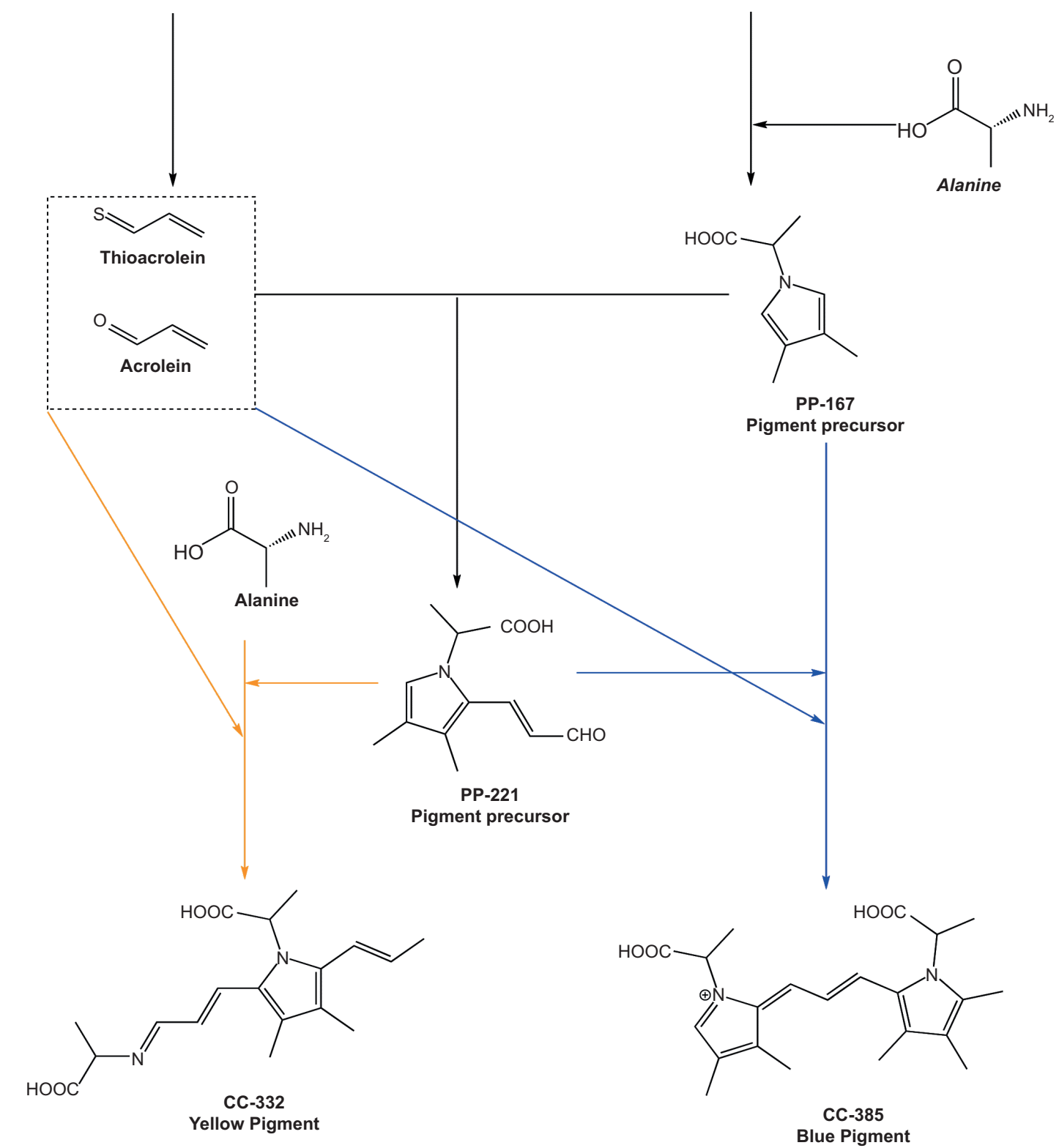

Alanine

Figure 4. Formation of yellow (CC-332) and blue (CC-385) pigments from alliin and isoalliin. Other yellow and blue pigments can be formed, not shown in the figure. 


\section{Formation of pigments}

Thiosulfinates are highly reactive, and thus they easily undergo nonenzymatic reactions yielding numerous sulfur-containing compounds responsible for sensorial attributes and bioactivities of Allium plants (Yoshimoto et al., 2019). Examples are acyclic sulfides, dithiines, and thiolanes that demonstrate bioactive properties similar to those of allicin (Block et al., 2018; Kubec et al., 2018; Martins et al., 2016; Štefanova et al., 2019).

1-Propenyl-containing thiosulfinates ("color developers") are converted into $\mathrm{N}$-substituted 3,4-dimethylpyrroles, also called pigment precursors (PPs), which can further react with different (thio)carbonyl compounds generating colored compounds that are responsible for the pigmentation of many Allium bulbs, including garlic (Allium sativum), onion (A. cepa), and leek (A. porrum). Among these species, the biosynthetic pathway of these pyrroles is very similar even if it leads to different pigmentations, typically green for garlic and pink/red for onion and leek (Comparini et al., 2018; Kubec et al., 2015, 2017). On the other hand, the red pigment formed upon crushing of another Allium species, giant onion (A. giganteum), is not derived from isoalliin but from a different amino acid precursor, S-(2-pyrrolyl)cysteine sulfoxide (Kučerová et al., 2011).

In general, almost all abundant free amino acids present in onion, leek, and garlic, including alanine, glutamine, glutamic acid, asparagine, aspartic acid, arginine, and lysine, are largely involved in the production of pigments (Cho et al., 2009; Kubec and Velíšek, 2007; Lee et al., 2013). However, it has been established that different pigments and color intensities are related to different amino acids involved in formation of pyrroles. In 2010, Lee and colleagues detected several pink-red pigments, originated from onion juice added with 21 free amino acids, indicating that onion discoloration could be due to these different pigments. Lee et al. (2010) also demonstrated that some amino acids could be the precursors of more than one pigment, while others, such as histidine, serine, and cysteine, are not involved in the biosynthesis of pigments. In another study with hydrophobic amino acids, it was hypothesized that the intensity of garlic greening could be related to the dimension of the amino acid $\mathrm{R}$ group, namely, the smaller the size of the $\mathrm{R}$ group, the larger the color intensity (Wang et al., 2008b). Nevertheless, this hypothesis was not confirmed for hydrophilicamino acids as, in a following study, glutamic acid yielded a more intense green color compared to asparagine, which has a bigger R-group (Hu et al., 2010).

The typical discoloration that occurs in garlic cloves is represented by the development of a green pigmentation (Figure 1). This color is not due to the production of green pigments but rather arises from a mixture of yellow and blue pigments, originating following different pathways (Wang et al., 2008b). Even if a full consensus has not been reached on the single step, proposed mechanisms suggest that both alliin and isoalliin should be present for the onset of green coloration (Imai et al., 2006a; Kubec et al., 2017; Wang et al., 2008; Zang et al., 2013). According to Wang and colleagues (2008), yellow pigments result from the interaction between precursors derived from isoalliin and pyruvic acid originated from alliinase activity (Figure 2). In the same study, precursors derived from different amino acids (PPAA) give rise to yellow pigments absorbing visible light in the range of $418-460 \mathrm{~nm}$, following at $440 \mathrm{~nm}$ this order of intensity: PP-Ala > PP-Val > PP-Gly > PP-Ile > PP-Leu > PP-Phe. Conversely, the blue pigments contributing to green color were attributed to the interaction between different precursors and allicin. Even if several precursors developed a blue dye, only PP-Gly, PP-Ala, and PP-Val could determine a significant blue pigmentation in garlic (absorption in the range 590-610 $\mathrm{nm})$. However, owing to their instability, blue dyes could in part be degraded into their yellow analogues (Wang et al., 2008; Zang et al., 2013), although it is unlikely that this hypothesized phenomenon is sufficient to prevent garlic discoloration.

Recently, a slightly different mechanism for the synthesis of both yellow and blue pigments was proposed by Kubec and colleagues (2017). In their study, two precursors and six color compounds $(\mathrm{CC})$ were identified after a reaction between garlic extract and the enzyme alliinase. The proposed pathway for the formation of these color compounds (CC-332 and CC-385) should not involve pyruvic acid and exclude the possibility of mutual interconversion of blue- and yellow-colored species (Figure 4).

\section{The control of garlic discoloration}

With the exception of "Laba" preparation, in which garlic greening is desired (Tao et al., 2016), this phenomenon strongly affects the consumers' perception, reducing garlic marketability (Zang et al., 2013). Different strategies have been adopted by farmers, sellers, and retailers to control greening, including management of environmental conditions during storage and usage of additives added directly on garlic cloves (Madhu et al., 2019).

\section{Discoloration control during fresh garlic storage}

Discoloration in garlic is affected by several environmental variables that should be controlled during its storage and processing (Zang et al., 2013). Among these variables, acting on temperature offers the possibility of 
controlling the activity of GGT enzyme involved in the biosynthesis of greening precursors $S$-alk(en)ylcysteine sulfoxides. Indeed, the inhibition of this enzyme would lead to an early interruption of the pigments' biosynthesis pathway. To prevent germination, garlic is usually stored at a temperature of around $-3^{\circ} \mathrm{C}$ for up to 9 months (Volk et al., 2004). Under these conditions the GGT enzyme (also involved in germination) is almost inactive, resulting in low alliin and isoalliin accumulation (Lancaster and Shaw, 1991). After sale, storage of garlic at refrigeration temperatures $\left(0-12^{\circ} \mathrm{C}\right)$ should be avoided, because the enzyme establish its maximum activity at $4{ }^{\circ} \mathrm{C}$, thus resulting in a high production rate of $S$-alk(en)ylcysteine sulfoxides. It was demonstrated that, upon a long-term refrigerated storage, garlic cloves developed, after crushing, much greener dye compared to those stored for a shorter time at the same conditions. On the contrary, it was observed that storing garlic at $35^{\circ} \mathrm{C}$ drastically reduced the activity of GGT, resulting in the decrease of greening and improvement in product's shelf-life (Li et al., 2008). Despite the fact that temperature of $35^{\circ} \mathrm{C}$ appears to be optimum for alliinase activity (Mishra et al., 2001), the concentration of its substrate ( $S$-alk(en)ylcysteine sulfoxides) is reduced due to the thermal inhibition of GGT. In addition, the temperature of $35^{\circ} \mathrm{C}$ favors the spontaneous conversion of isoalliin (one of the major $S$-alk(en)ylcysteine sulfoxides) into cycloalliin, which is not involved in the greening phenomenon as it is not a substrate of alliinase. This mechanism could be exploited also in the case of refrigerated storage. Indeed, if cold storage conditions (below $0^{\circ} \mathrm{C}$ ) are not available, cloves can be stored at refrigerated conditions and then subjected to warm storage $\left(35-40^{\circ} \mathrm{C}\right.$ for 2 weeks) to allow the conversion of isoalliin to cycloalliin and produce garlic bulbs without noticeable changes in color (Yamazaki et al., 2012).

Another important factor that could be controlled during storage is the concentration of oxygen and carbon dioxide present in the atmosphere. Indeed, the storage in controlled atmosphere, normally applied to prevent spoilage, also aids in controlling garlic greening. Encouraging results in terms of final quality, sprout growth, spoilage delay, and discoloration of garlic bulbs have been reported after keeping garlic cloves for up to 6.5 months at $0-1{ }^{\circ} \mathrm{C}$ in a controlled atmosphere containing $0.5 \% \mathrm{O}_{2}$, 5-15\% $\mathrm{CO}_{2}$, and $60-70 \%$ relative humidity, compared to normal atmosphere and modified atmosphere, in which only $\mathrm{O}_{2}$ or $\mathrm{CO}_{2}$ concentration was adjusted $\left(0.5 \% \mathrm{O}_{2} /\right.$ normal $\mathrm{CO}_{2}$ and normal $\mathrm{O}_{2} / 10 \% \mathrm{CO}_{2}$ ) (Cantwell et al., 2003). The positive effect of low $\mathrm{O}_{2} /$ high $\mathrm{CO}_{2}$ conditions combined with cold storage was also demonstrated for onion, in which decrease in discoloration was attributed to a slowdown of alliinase activity (Uddin and MacTavish, 2003).
However, it is important to consider that the control of both temperature and atmosphere composition during storage does not appear to be resolutive; indeed, even if the activity of enzymes is inhibited and the production of $S$-alk(en)ylcysteine sulfoxides is limited, all conditions favorable for developing greening phenomenon could be restored at the end of the storage and/or during transportation and retail.

\section{Discoloration control during fresh garlic processing}

In Mediterranean countries, garlic is primarily consumed fresh, while in Asia and other regions it is generally processed to obtain products such as paste, powder, puree, and macerate cloves (Li et al., 2015). Owing to crushing, these processes could increase the risk of greening of these products. Nevertheless, the addition of additives and/or the adoption of specific techniques, which are normally not available for fresh garlic, during the production process can offer some possibilities to control discoloration.

\section{Control by acidification, heat treatments, and drying}

The level of acidity ( $\mathrm{pH}$ ) affects both enzymatic and nonenzymatic reactions leading to pigment formation in garlic. Nonenzymatic reactions are promoted in strong acidic conditions ( $\mathrm{pH} 2-3$ ), but they still take place at $\mathrm{pH}$ 5-6, which makes these difficult to control by acting on acidity (Zang et al., 2013). Conversely, enzymatic reactions, in general, and alliinase activity, in particular, are inhibited at $\mathrm{pH}<3$. Since the normal $\mathrm{pH}$ of garlic is in the range 4.5-5.5, acidification can represent a relevant tool to control greening of some garlic-based products (Bai et al., 2006). The $\mathrm{pH}$ drop could be achieved by adding acidifying agents, such as organic acids, during maceration or immediately after cutting or crushing, resulting in the inhibition of alliinase activity. However, it is important to consider that monocarboxylic acids such as acetic acid are great promoters of garlic greening, since they facilitate tonoplast permeability, allowing alliinase to come in contact with its substrate $S$-alk(en)ylcysteine sulfoxides (Zang et al., 2013). As observed previously, once imported into the cell, the dissociated form of acetic acid is able to damage tonoplast and other cellular structures (Bai et al., 2006). Indeed, for some processed garlic products (such as "Laba"), maceration of cloves with vinegar promotes the desired greening in spite of low $\mathrm{pH}$ (between 2 and 3) of vinegar (Li et al., 2015). This is due to the slow acidification of the inner parts of intact cloves during maceration that allows the acetic acid to permeate tonoplast before alliinase inhibition. Therefore, control of greening by organic acid additions should involve only non-monocarboxylic acids such as ascorbic acid, malic acid, and citric acid, which do not affect tonoplast's integrity, possibly because plants develop specific systems to 
manage these acids stored naturally in vacuole (Bai et al., 2006). Indeed, when tested on garlic, ascorbic acid, malic acid, and citric acid reported a substantial inhibition of green color development (Bai et al., 2006; Kim et al., 1999).

As many other enzymes, GGT and alliinase can be inactivated by high temperature treatments. In fact, in garlic processing the inactivation of both the enzymes can be achieved by blanching. This treatment involves heating at $70-100^{\circ} \mathrm{C}$ for $1-30 \mathrm{~min}$ with hot water or microwaves and is applied to processed vegetables to achieve enzymatic inactivation and reduce microbial contamination. Blanching conditions are poorly tolerated by both GGT and alliinase, whose activity rapidly drops after $10 \mathrm{~min}$ at $70^{\circ} \mathrm{C}$ (Huang et al., 2019; Yin et al., 2009), whereas complete inactivation was reported after $30 \mathrm{~min}$ at $70^{\circ} \mathrm{C}$ for GGT and after $15 \mathrm{~min}$ at $90^{\circ} \mathrm{C}$ for alliinase (Mochizuki et al., 1988; Rejano et al., 1997). However, heat treatments also cause a decrease in the contents of allicin and other antioxidant molecules, leading to impoverishment in the bioactive properties of garlic. A recent study calculated the kinetics of GGT and alliinase inactivation along with that of decrease in concentration and antioxidant activity of allicin (Huang et al., 2019). Following a holistic approach, these authors proposed a blanching treatment of $4 \mathrm{~min}$ at $90^{\circ} \mathrm{C}$, which seemed to be a good compromise to obtain an effective enzyme inactivation and limited losses of allicin and other valuable compounds. Nevertheless, it should be established that blanching is effective only if performed before the accumulation of thiosulfinates formed by the catalytic action of alliinase because the following nonenzymatic reactions leading to production of pigments have established to be strongly promoted by high temperatures (Imai et al., 2006b).

While the techniques to control greening based on $\mathrm{pH}$ modification and heat treatments negatively reduce the accumulation of allicin, drying could represent a compromise between the control of greening and the accumulation of bioactive compounds. It is well known that the drying process can limit many enzymatic and nonenzymatic reactions responsible of food spoilage and degradation by decreasing the activity of water (Baysal et al., 2003; Fante and Noreña, 2015). In the case of garlic, recent studies have investigated the possibility to preserve its original color while maintaining a good content of allicin by drying fresh garlic immediately after cutting. All these studies established that the involvement of allicin (which was formed soon upon cutting) in pigment formation could be dramatically reduced by a drop in activity of water (Baysal et al., 2003; Duan et al., 2015; Fante and Noreña, 2015; illter et al., 2018; Utama-Ang et al., 2018). Conventional air drying of garlic was also compared with more sophisticated techniques such as freeze-drying and microwave treatment. The last two methods reported effective results in terms of color maintenance by reducing the effect of the Maillard reaction, which is promoted at high temperatures/for long durations typical of conventional drying. In particular, microwave drying of garlic appeared to be suitable for industrial applications as it may offer the possibility of reducing treatment time and energy costs (Baysal et al., 2003; Ilter et al., 2018).

\section{Control by addition of additives}

As mentioned above, isoalliin is involved in the discoloration process of garlic and other Allium plants. In onion, its corresponding sulfenic acid (1-propenesulfenic acid) can be converted into di-1-propenyl thiosulfinate (a pigment precursor) by a nonenzymatic reaction. In Allium species, this step could be partially inhibited by the action of the enzyme lachrymatory factor synthase (LFS). Indeed, LFS catalyzes the conversion of 1-propenylsulfenic acid into propanthialS-oxide (lachrymatory factor). Therefore, LFS is able to remove isoalliin from the pathway of formation of pigments, thus inhibiting discoloration (Cho et al., 2012a; Zang et al., 2013). By considering this discovery and that isoalliin is a key compound for garlic greening (Lukes, 1986), some authors hypothesized that the addition of LFS in garlic (where it is not naturally present) could prevent the appearance of green pigmentation. With the aim to suggest the application of LFS as a natural additive, in these studies dried onion was used as a source of LFS instead of adding the purified enzyme. It was reported that 5-15 g of onion powder per kilogram of fresh garlic prevented greening by decreasing the content of isoalliin-derived thiosulfinate (Cho et al., 2012a; Lee et al., 2012). Compared to others, this approach has the advantage of preserving the antioxidant activity of allicin because it allows this compound to remain available in garlic.

Other compounds have been applied to protect garlic from both greening and browning (Zang et al., 2013). Addition of cysteine, ascorbic acid, sodium metabisulfite, and trisodium phosphate resulted in a significant drop of green pigmentation in ground garlic, and sodium metabisulfite was the most effective of all these compounds. In addition, it was demonstrated that binary, ternary, and quaternary mixtures of these additives, if containing sodium metabisulfite, were more effective than individual compounds in preventing both greening and browning (Kim et al., 1999).

\section{Control by other technologies}

The need to control greening without affecting sensory properties of garlic has led to the application of other more advanced technologies. $\gamma$-Irradiation is a 
widespread technology that is used to process plant foods (for review, see Farkas, 2006). First attempts were made to evaluate the impact of application of both $\gamma$-irradiation and high hydrostatic pressure on development of green color during storage of garlic (Ceci et al., 1992; Hong and Kim, 2001). Thanks to the slowing of certain metabolic processes and inhibition of enzymes such as polyphenol oxidase, both technologies were effective in preventing germination, senescence, and browning (Farkas, 2006; Hong and Kim, 2001; madhu et al., 2019), but no impact on the development of greening and its related enzymes was recorded. In addition, high-pressure treatments probably damaged garlic tissues, thus promoting the contact between alliinase and its substrates $S$-alk(en)ylcysteine sulfoxides (Tao et al., 2016).

More recent studies have evaluated the impact of light of different spectra on developing greening during storage of garlic (Comparini et al., 2018; He et al., 2019). A significant delay in the process of greening was reported after the application of green, blue, and yellow lights, and a combination of them, during storage. Even if not resolutive, light-control could represent an additional tool to be integrated in strategies aimed to prevent greening. Indeed, the application of light has a negligible impact on garlic integrity, thus making this technique accessible and easily acceptable.

\section{Conclusions}

Greening represents a major technological problem significantly affecting garlic marketability. In spite of some missing information, great advancements have been made during the last decade in understanding the biosynthetic pathways leading to the formation of pigments in Allium plants. Some of these findings have improved the available strategies aimed at controlling garlic greening. Innovative approaches that would deserve more attention and research are those based on the use of natural additives, as in the case of dried onion addition. However, new strategies to be developed to prevent greening of garlic should in any case also consider the preservation of the compounds known to impact both consumer health and flavor of garlic.

\section{References}

Aghajanzadeh T.A., Reich M., Hawkesford M.J. and Burow, M. 2019. Sulfur metabolism in Allium cepa is hardly affected by chloride and sulfate salinity. Archives of Agronomy and Soil Science 65(7):945. https://doi.org/10.1080/03650340.2018.154.0037

Bai B., Li L., Hu X., Wang Z. and Zhao G. 2006. Increase in the permeability of tonoplast of garlic (Allium sativum) by monocarboxylic acids. Journal of Agricultural and Food Chemistry 54(21):8103. https://doi.org/10.1021/jf061628h
Banerjee S.K., Mukherjee P.K. and Maulik S.K. 2003. Garlic as an antioxidant: the good, the bad and the ugly. Phytotherapy Research 17(2):97. https://doi.org/10.1002/ptr.1281

Baysal T., Icier F., Ersus S. and Yildiz H. 2003. Effects of microwave and infrared drying on the quality of carrot and garlic. Journal of European Food Research and Technology 218(1):68. https://doi. org/10.1007/s00217-003-0791-3

Binder S. 2010. Branched-chain amino acid metabolism in Arabidopsis thaliana. Arabidopsis Book 8:e0137. https://doi. org/10.1199/tab.0137

Block E. 1992. The organosulfur chemistry of the genus Allium implications for the organic chemistry of sulfur. Angewandte Chemie International Edition English. 31(9):1135. https://doi. org/10.1002/anie.199211351

Block E. 2010. "Garlic and Other Alliums - the Lore and the Science". Royal Society of Chemistry (RSC), Cambridge, UK.

Block E., Dethier B., Bechand B., Cotelesage J.J.H., George G.N., Goto K., et al. 2018. Ajothiolanes: 3,4-dimethylthiolane natural products from garlic (Allium sativum). Journal of Agricultural and Food Chemistry 66(39):10193. https://doi.org/10.1021/acs. jafc. 8 b03638

Borlinghaus J., Albrecht F., Gruhlke M.C.H., Nwachukwu I.D. and Slusarenko A.J. 2014. Allicin: chemistry and biological properties. Molecules 19(8):12591. https://doi.org/10.3390/ molecules190812591

Cantwell M.I., Hong G., Kang J. and Nie X. 2003. Controlled atmospheres retard sprout growth, affect compositional changes, and maintain visual quality attributes of garlic. Acta Horticulturae 600:791. https://doi.org/10.17660/ActaHortic.2003.600.122

Ceci L.N., Curzio O.A. and Pomilio A.B. 1992. Effects of irradiation and storage on the $\gamma$-glutamyl transpeptidase activity of garlic bulbs cv 'red.' Journal of the Science of Food and Agriculture 59(4):505. https://doi.org/10.1002/jsfa.2740590413

Cho J., Lee E.J., Yoo K.S. and Lee S.K. 2012. Role of precursors on greening in crushed garlic (Allium sativum) bulbs, and its control with freeze-dried onion powder. Journal of the Science of Food and Agriculture 92(2):246. https://doi.org/10.1002/jsfa.4568

Cho J., Lee E.J., Yoo K.S., Lee S.K. and Patil B.S. 2009. Identification of candidate amino acids involved in the formation of blue pigments in crushed garlic cloves (Allium sativum L.). Journal of Food Science 74(1):C11. https://doi. org/10.1111/j.1750-3841.2008.00986.x

Cho J., Park M., Choi D. and Lee S.K. 2012. Cloning and expression of $\gamma$-glutamyl transpeptidase and its relationship to greening in crushed garlic (Allium sativum) cloves. Journal of the Science of Food and Agriculture 92(2):253. https://doi.org/10.1002/jsfa.4610

Comparini D., Nguyen H.T. H., Ueda K., Moritaka K., Kihara T. and Kawano T. 2018. Effect of different light spectra on the pigmentation of stored elephant garlic. Journal of the Science of Food and Agriculture 98(7):2598. https://doi.org/10.1002/jsfa.8752

Duan X., Liu W.C., Ren G.Y., Yang X.T. and Liu Y.H. 2015. Atmospheric freeze drying garlic slices based on freezing point depression. International Journal of Agricultural and Biological Engineering 8(4):133.

Fante L. and Noreña C.P.Z. 2015. Quality of hot air dried and freeze-dried of garlic (Allium sativum L.). Journal of Food 
Science and Technology 52(1):211. https://doi.org/10.1007/ s13197-013-1025-8

FAOSTAT. 2016. Statistical database. Available at: www.fao.org/ faostat/

Farkas J. 2006. Irradiation for better foods. Trends in Food Science and Technology. 17(4):148. https://doi.org/10.1016/j. tifs.2005.12.003

Granroth B. 1970. Biosynthesis and decomposition of cysteine derivatives in onion and other Allium species. Annales Academiae Scientiarum Fennicae-Chemistry 154:4.

Grzam A., Martin M.N., Hell R. and Meyer A.J. 2007. $\gamma$-Glutamyl transpeptidase GGT4 initiates vacuolar degradation of glutathione S-conjugates in Arabidopsis. FEBS Letters 581(17):3131. https://doi.org/10.1016/j.febslet.2007.05.071

He Y., Fan G.J., Wu C., Kou X. and Li T. 2019. Influence of illumination on the greening and relative enzyme activity of garlic puree. Journal of Food Biochemistry 43(7):e12871. https://doi. org/10.1111/jfbc.12871

Hong S.I. and Kim D.M. 2001. Storage quality of chopped garlic as influenced by organic acids and high-pressure treatment. Journal of the Science of Food and Agriculture 81(4):397. https://doi.org/10.1002/1097-0010(200103)81:4<397::AID-JSFA831>3.0.CO;2-R

Hu D., Zhang J., Zhang T., Dong J., Leng X. and Zhao G. 2010. Characterization of yellow pigments formed on reaction of 2 - $(1 \mathrm{H}$-pyrrolyl)carboxylic acids with pyruvic acid in garlic greening model systems. Food Research International 43(3):915. https://doi.org/10.1016/j.foodres.2009.12.009

Huang Z., Zhou Q., Wu W.L., Wan J. and Jiang A.M. 2019. Thermal kinetics of enzyme inactivation, color changes, and allicin degradation of garlic under blanching treatments. Journal of Food Process Engineering 42(3):e12991. https://doi.org/10.1111/ jfpe.12991

İlter I., Akyıl S., Devseren E., Okut D., Koç M. and Kaymak Ertekin F. 2018. Microwave and hot air drying of garlic puree: drying kinetics and quality characteristics. Journal of Heat and Mass Transfer 54(7):2101. https://doi.org/10.1007/s00231-018-2294-6

Imai S., Akita K., Tomotake M. and Sawada H. 2006a. Model studies on precursor system generating blue pigment in onion and garlic. Journal of Agricultural and Food Chemistry 54(3):848. https://doi.org/10.1021/jf051980f

Imai S., Akita K., Tomotake M. and Sawada H. 2006b. Identification of two novel pigment precursors and a reddish-purple pigment involved in the blue-green discoloration of onion and garlic. Journal of Agricultural and Food Chemistry 54(3):843. https:// doi.org/10.1021/jf0519818

Imai S., Tsuge N., Tomotake M., Nagatome Y., Sawada H., Nagata T., et al. 2002. An onion enzyme that makes the eyes water. Nature 419(6908):685. https://doi.org/10.1038/419685a

Kim W. J., Cho J.S. and Kim K.H. 1999. Stabilization of ground garlic color by cysteine, ascorbic acid, trisodium phosphate and sodium metabisulfite. Journal of Food Quality 22(6):681. https:// doi.org/10.1111/j.1745-4557.1999.tb00281.x

Kopec A., Piatkowska E., Leszczynska T. and Sikora E. 2013. Healthy properties of garlic. Current Nutrition \& Food Science 9(1):59. https://doi.org/10.2174/15734.0113804810888
Kubec R., Curko P., Urajová P., Rubert J. and Hajšlová J. 2017. Allium discoloration: color compounds formed during greening of processed garlic. Journal of Agricultural and Food Chemistry 65(48):10615. https://doi.org/10.1021/acs.jafc.7b04609

Kubec R., Hrbáčová M., Musah R.A. and Velí̌̌ek J. 2004. Allium discoloration: precursors involved in onion pinking and garlic greening. Journal of Agricultural and Food Chemistry 52(16):5089. https://doi.org/10.1021/jf04.97455

Kubec R., Štefanová I., Moos M., Urajová P., Kuzma M. and Zápal J. 2018. Allithiolanes: nine groups of a newly discovered family of sulfur compounds responsible for the bitter off-taste of processed onion. Journal of Agricultural and Food Chemistry 66(33):8783. https://doi.org/10.1021/acs.jafc.8b03118

Kubec R., Urajová P., Lacina O., Hajšlová J., Kuzma M. and Zápal J. 2015. Allium discoloration: color compounds formed during pinking of onion and leek. Journal of Agricultural and Food Chemistry 63(46):10192. https://doi.org/10.1021/acs. jafc. 5 b0 04564

Kubec R. and Velíšek J. 2007. Allium discoloration: the color-forming potential of individual thiosulfinates and amino acids: structural requirements for the color-developing precursors. Journal of Agricultural and Food Chemistry 55(9):3491. https://doi. org/10.1021/jf070040n

Kučerová P., Kubec R., Šimek P., Václavík L. and Schraml J. 2011. Allium discoloration: the precursor and formation of the red pigment in giant onion (Allium giganteum Regel) and some other subgenus Melanocrommyum species. Journal of Agricultural and Food Chemistry 59(5):1821. https://doi.org/10.1021/jf104195k

Lancaster J.E. and Collin H.A. 1981. Presence of alliinase in isolated vacuoles and of alkyl cysteine sulphoxides in the cytoplasm of bulbs of onion (Allium cepa). Plant Science Letters 22(2):169. https://doi.org/10.1016/0304-4211(81)90139-5

Lancaster J.E., and Shaw M.L. 1989. $\gamma$-Glutamyl peptides in the biosynthesis of S-alk(en)yl-l-cysteine sulphoxides (flavour precursors) in Allium. Phytochemistry 28(2):455. https://doi. org/10.1016/0031-9422(89)80031-7

Lancaster J.E. and Shaw M.L. 1991. Metabolism of $\gamma$-glutamyl peptides during development, storage and sprouting of onion bulbs. Phytochemistry 30(9):2857. https://doi.org/10.1016/ S0031-9422(00)98212-8

Lanzotti V. 2006. The analysis of onion and garlic. Journal of Chromatography A 1112(1-2):3. https://doi.org/10.1016/j. chroma.2005.12.016

Lee J.Y., Lee H.J. and Kyung K.H. 2013. Green pigmentation characteristics of amino compounds with thiosulfinates obtained from garlic (Allium sativum L.). Food Science and Biotechnology 22(2):373. https://doi.org/10.1007/s10068-013-0090-0

Lee E.J., Yoo K.S. and Patil B.S. 2010. Identification of candidate amino acids involved in the formation of pink-red pigments in onion (Allium cepa L.) juice and separation by HPLC. Journal of Food Science 75(8):C684. https://doi. org/10.1111/j.1750-3841.2010.01814.x

Lee E.J., Yoo K.S. and Patil B.S. 2012. Freeze-dried fresh onion powder prevents green discolouration (greening) in macerated garlic. Food Chemistry 131(2):397. https://doi.org/10.1016/j. foodchem.2011.08.071 
Li L., Hu D., Jiang Y., Chen F., Hu X. and Zhao G. 2008. Relationship between $\gamma$-glutamyl transpeptidase activity and garlic greening, as controlled by temperature. Journal of Agricultural and Food Chemistry 56(3):941. https://doi.org/10.1021/jf072470j

Li L., Wang D., Li X., Wang Y. and Ju X. 2015. Elucidation of colour development and microstructural characteristics of Allium sativum fumigated with acetic acid. International Journal of Food Science and Technology 50(5):1083. https://doi.org/10.1111/ijfs.12751

Lukes T.M. 1986. Factors governing the greening of garlic puree. Journal of Food Science 51(6):1577. https://doi.org/10.1111/ j.1365-2621.1986.tb13869.x

Madhu B., Mudgal V.D. and Champawat P.S. 2019. Storage of garlic bulbs (Allium sativum L.): a review. Journal of Food Process Engineering 42(6):e13177. https://doi.org/10.1111/jfpe.13177

Martins N., Petropoulos S. and Ferreira I.C.F.R. 2016. Chemical composition and bioactive compounds of garlic (Allium sativum L.) as affected by pre- and post-harvest conditions: a review. Food Chemistry 211:41. https://doi.org/10.1016/j. foodchem.2016.05.029

Mishra R., Upadhyay S.K. and Maheshwari P.N. 2001. Stability of allicin in garlic - a kinetic study. Indian Journal of Chemical Technology 8(3):195.

Mochizuki E., Nakayama A., Kitada Y., Saito K., Nakazawa H., Suzuki S. and Fujita M. 1988. Liquid chromatographic determination of alliin in garlic and garlic products. Journal of Chromatography 455:271. https://doi.org/10.1016/S0021-9673(01)82125-7

Rahman M.S. 2007. Allicin and other functional active components in garlic: health benefits and bioavailability. International Journal of Food Properties. 10(2):245. https://doi. org/10.1080/10942910601113327

Rejano L., Sanchez A.H., De Castro A. and Montano A. 1997. Chemical characteristics and storage stability of pickled garlic prepared using different processes. Journal of Food Science 62(6):1120. https://doi.org/10.1111/j.1365-2621.1997.tb12226.x

Shimon L.J.W., Rabinkov A., Shin I., Miron T., Mirelman D., Wilchek M., et al. 2007. Two structures of alliinase from Alliium sativum L.: apo form and ternary complex with aminoacrylate reaction intermediate covalently bound to the PLP cofactor. Journal of Molecular Biology 366(2):611. https://doi. org/10.1016/j.jmb.2006.11.041

Silvaroli J.A., Pleshinger M.J., Banerjee S., Kiser P.D. and Golczak M. 2017. Enzyme that makes you cry - crystal structure of lachrymatory factor synthase from Allium cepa. ACS Chemical Biology 12(9):2296. https://doi.org/10.1021/acschembio.7b00336

Speranza G. and Morelli C.F. 2012. $\gamma$-Glutamyl transpeptidasecatalyzed synthesis of naturally occurring flavor enhancers. Journal of Molecular Catalysis B: Enzymatic 84:65. https://doi. org/10.1016/j.molcatb.2012.03.014

Štefanová I., Zápal J., Moos M., Kuzma M. and Kubec R. 2019. Isoalliin-derived thiolanes formed in homogenized onion. Journal of Agricultural and Food Chemistry 67(35):9895. https:// doi.org/10.1021/acs.jafc.9b01384.

Stoll A. and Seebeck E. 1948. Allium compounds. I. Alliin, the true mother compound of garlic oil. Helvetica Chimica Acta 31:189. https://doi.org/10.1002/hlca.19480310140
Stoll A. and Seebeck E. 1949a. Allium compounds. II. Enzymatic degradation of alliin and the properties of alliinase. Helvetica Chimica Acta 32:197. https://doi.org/10.1002/hlca.19490320129 Stoll A. and Seebeck E. 1949b. Allium compounds. III. Specificity of alliinase and synthesis of compounds related to alliin. Helvetica Chimica Acta. 32:866. https://doi.org/10.1002/hlca.19490320330

Stoll A. and Seebeck E. 1951. Chemical investigations on alliin, the specific principle of garlic. In "Advances in Enzymology and Related Areas of Molecular Biology," Vol. 11. F.F. Nord (Ed.), p. 377. John Wiley, New York, NY. https://doi. org/10.1002/9780470122563.ch8

Suzuki T., Sugii M. and Kakimoto T. 1962. Metabolic incorporation of L-valine-[14C] into S-(2-carboxypropyl)glutathione and S-(2carboxypropyl)cysteine in garlic. Chemical and Pharmaceutical Bulletin 10(4):328. https://doi.org/10.1248/cpb.10.328

Tao D., Zhou B., Zhang L., Hu X., Liao X. and Zhang Y. 2016. "Laba” garlic processed by dense phase carbon dioxide: the relation between green colour generation and cellular structure, alliin consumption and alliinase activity. Journal of the Science of Food and Agriculture 96(9):2969. https://doi.org/10.1002/jsfa.7463

Uddin M.M. and MacTavish H.S. 2003. Controlled atmosphere and regular storage-induced changes in S-alk(en)yl-L-cysteine sulfoxides and alliinase activity in onion bulbs (Allium cepa L. cv. Hysam). Postharvest Biology and Technology 28(2):239. https:// doi.org/10.1016/S0925-5214(02)00195-3

Utama-ang N., Cheewinworasak T., Simawonthamgul N. and Samakradhamrongthai R.S. 2018. Effect of drying condition of Thai garlic (Allium sativum L.) on physicochemical and sensory properties. International Food Research Journal 25(4):1365.

Volk G.M., Rotindo K.E. and Lyons W. 2004. Low-temperature storage of garlic for spring planting. Horticulture Science 39(3):571. https://doi.org/10.21273/HORTSCI.39.3.571

Wang D., Nanding H., Han N., Chen F. and Zhao G. 2008. 2 -(1H-pyrrolyl)carboxylic acids as pigment precursors in garlic greening. Journal of Agricultural and Food Chemistry 56(4):1495. https://doi.org/10.1021/jf073025r

Yamazaki Y., Yamamoto T. and Okuno T. 2012. Causes and remedies for green discoloration of processed garlic puree: effects of storage conditions on ingredient bulbs. Food Science and Technology Research 18(2):187. https://doi.org/10.3136/fstr.18.187

Yin J., Zhu J., Fu L. and Li J. 2009. Purification and properties of $\gamma$-glutamyltranspeptidase from Lentinula edodes. Acta Edulis Fungi. 16:31.

Yoshimoto N., Onuma M., Mizuno S., Sugino Y., Nakabayashi R., Imai S., et al. 2015. Identification of a flavin-containing S-oxygenating monooxygenase involved in alliin biosynthesis in garlic. Plant Journal 83(6):941. https://doi.org/10.1111/tpj.12954.

Yoshimoto N., Saito K. and Kopriva S. 2019. S-Alk(en)ylcysteine sulfoxides in the genus Allium: proposed biosynthesis, chemical conversion, and bioactivities. Journal of Experimental Botany 70(16):4123. https://doi.org/10.1093/jxb/erz243

Zang J., Wang D. and Zhao G. 2013. Mechanism of discoloration in processed garlic and onion. Trends in Food Science and Technology 30(2):162. https://doi.org/10.1016/j.tifs.2013.01.008 